\title{
SISTEM INFORMASI PENGOLAHAN DATA KELULUSAN SISWA NON-FORMAL BERBASIS WEB PADA DINAS PENDIDIKAN NASIONAL KOTA TERNATE
}

\section{DATA PROCESSING INFORMATION SYSTEM FOR NON-FORMAL STUDENTS BASED ON WEB IN NATIONAL EDUCATION DEPARTMENT OF CITY TERNATE}

\author{
Vivin Ambar ${ }^{1}$, Arisandy Ambarita ${ }^{2}$ \\ Program Studi Manajemen Informatika, \\ Politeknik Sains dan Teknologi Wiratama Maluku Utara \\ vivinambar21@gmail.com
}

\begin{abstract}
Abstrak
Pendidikan non-formal sebagai salah satu bentuk layanan pendidikan yang dibutuhkan keberadaannya oleh masyarakat. Dinas Pendidikan Nasional Kota Ternate merupakan salah satu instansi pemerintah yang berperan penting dalam mengimplementasi pelayanan pendidikan non-formal dibidang PNFI (Pendidikan Non-Formal dan Informal). Dalam Pengolahan data hasil kelulusan siswa non-formal pada Dinas Pendidikan Nasional masih bersifat konvensional, dimana proses penginputan, penyimpanan dan informasi hasil kelulusan masih dilakukan secara manual dan tertulis. Proses pencarian data hasil kelulusan siswa membutuhkan waktu yang sangat lama dikarenakan data hasil kelulusan siswa tersimpan pada arsip-arsip dan harus dibuka satu per satu, dan informasi hasil kelulusan masih diumumkan di papan pengumuman pada Dinas Pendidikan Nasional, sehingga siswa harus datang untuk melihat hasil pengumuman tersebut. Penilitian ini memberikan kemudahan pihak instansi untuk melakukan pengolahan data hasil kelulusan siswa nonformal dan mempermudah siswa dan orang tua untuk dapat melihat informasi hasil kelulusan pada website.
\end{abstract}

\section{Kata Kunci : Sistem Informasi, Pengolahan Data, Siswa Non-Formal}

\begin{abstract}
Non-formal education as one of the forms of educational services needed by the community, The National Education Department Of Ternate City is one of the government agencies that play an important role in implementing non-formal education services in the field of Nonformal and Informal Education. In the data processing of graduation result of non-formal students in National Education Department Of ternate City is still conventional, where the process of inputting, storage and information of graduation is still done manually and in writing, the process of searching the data of the students' graduation result takes a very long time due to the data of the students graduation Stored in the archives and must be opened one by one, and information on graduation results are still announced on the bulletin board at the National Education Office so that students must come to see the results of the announcement, this research provides convenience to the agency to perform processing data graduation Non-formal students and make it easier for students and parents to be able to view information on the results of the graduation on the website
\end{abstract}

Keyword: Information Systems, Data Processing, Student Non-Formal 


\section{PENDAHULUAN}

Kemajuan teknologi informasi mempengaruhi perkembangan pelayanan pendidikan dalam hal pengelolaan data, pengendalian interen dan peningkatan jumlah yang ada pada pendidikan dengan adanya kemajuan yang telah dicapai dalam pendidikan yang menyangkut pelayanan dan penyajian data berbasis komputer dalam menghasilkan laporan pendidikan.

Dalam UU No. 20 Tahun 2003 tentang SISDIKNAS, disebutan pendidikan adalah usaha sadar dan terencana untuk mewujudkan suasana belajar dan proses pembelajaran agar peserta didik secara aktif mengembangkan potensi dirinya untuk memiliki kekuatan spiritual keagamaan, pengendalian diri, kepribadian, kecerdasan, akhlak mulia, serta keterampilan yang diperlukan dirinya, masyarakat, bangsa dan negara.

Penyelenggaraan pendidikan di Indonesia secara umum dibedakan menjadi dua macam yaitu pendidikan formal dan pendidikan nonformal. Pendidikan formal mengacu pada PP No 19 Tahun 2005 adalah jalur pendidikan yang terstruktur dan berjenjang yang terdiri atas pendidikan dasar, pendidikan menengah, dan pendidikan tinggi. Sedangkan pendidikan nonformal adalah jalur pendidikan diluar pendidikan formal yang dapat dilaksanakan secara terstruktur dan berjenjang.

Pendidikan non-formal sebagai salah satu bentuk layanan pendidikan yang dibutuhkan keberadaannya oleh masyarakat. Pendidikan non-formal memiliki peran strategis dalam upaya memfasilitasi anak-anak yang putus sekolah (drop out). Pendidikan non-formal berfungsi memberi layanan pendidikan kepada masyarakat atau anak usia sekolah yang sudah menikah atau putus sekolah.
Untuk membentuk kelancaran dan keberhasilan layanan pendidikan nonformal, pemeritah melalui Kementrian Pendidikan dan Kebudayaan, Direktorat Jenderal, Pendidikan Dasar, Direktorat Pembinaan Sekolah memberikan Bantuan Sosial (Bansos) untuk Penyelenggaraan Pendidikan non-formal. Pemerintah memilliki kewajiban memberikan layanan pendidikan bagi masyarakat yang membutuhkan layanan pendidikan karena faktor sosial dan ekonomi

Pendidikan nonformal dan informal sebagai salah satu jalur sistem pendidikan nasional, memusatkan perhatiannya pada pelayanan bagi warga masyarakat yang tergolong kurang beruntung dimana salah satu programnya adalah pendidikan kesetaraan paket A, B, C yang terintegrasi keterampilan. Hal ini diperuntukkan bagi anak usia dini wajib belajar yang tidak tertampung di sekolah dan orang dewasa yang kebutuhan pendidikan menengahnya tidak dapat terpenuhi melalui jalur formal. Pendidikan kesetaraan paket A, B, C integrasi keterampilan berbasis potensi lokal memberikan ruang dan peluang seluas-luasnya bagi warga belajar ditempuhnya dalam jalur pendidikan.

Dinas Pendidikan Nasional Kota Ternate merupakan salah satu instansi pemerintah yang berperan penting dalam mengimplementasi pelayanan pendidikan nonformal di bidang PNFI (Pendidikan Non-Formal dan Informal). Pengelolaan data hasil kelulusan siswa non-formal sangat berperan penting dalam administrasi sebagai sumber informasi dalam rangka pembuatan laporan dan pertanggung jawaban secara efektif dan efisien. Dalam Pengolahan data hasil kelulusan siswa non-formal pada Dinas Pendidikan Nasional masih bersifat konvensional, dimana proses penginputan, 
penyimpanan dan informasi hasil kelulusan masih dilakukan secara manual dan tertulis, sehingga proses pencarian data hasil kelulusan siswa membutuhkan waktu lama karena data hasil kelulusan siswa tersimpan pada arsip-arsip dan harus dibuka satu per satu. Informasi hasil kelulusan masih diumumkan di papan pengumuman Dinas Pendidikan Nasional sehingga siswa tersebut harus datang untuk melihat hasil pengumuman tersebut

Dengan melihat masalah yang dihadapi oleh Dinas Pendidikan Nasional, maka peneliti mencoba membuat Sistem Informasi Pengolahan Data Hasil Kelulusan Siswa Non-Formal Berbasis Web. Web digunakan agar siswa atau orang tua dapat melihat hasil kelulusan dimana saja. Dengan adanya system ini dapat mempermudah pihak instansi dalam mengelola data hasil kelulusan serta memberikan informasi hasil kelulusan dengan cepat dan efisien.

\section{Rumusan Masalah}

Masalah dalam penelitian ini adalah bagaimana merancang Sistem Informasi Pengolahan Data Hasil Kelulusan Siswa Non-formal Pada Kantor Dinas Pendidikan Nasional Kota Ternate? Mengacu pada masalah tersebut, maka penelitian ini bertujuan memberikan kemudahan kepada pihak instansi untuk melakukan pengolahan data hasil kelulusan siswa non-formal dalam meningkatkan kinerja dan pelayanan di Dinas Pendidikan Nasional, serta mempermudah siswa dan orang tua untuk dapat melihat informasi hasil kelulusan pada website.

\section{LANDASAN TEORI Defenisi Sistem Informasi}

Sistem informasi menurut Burch dan Strater (1974 ) dalam Moekijat (2005), adalah kumpulan bagian-bagian yang formal dan sistematis yang melaksanakan operasi pengolahan data untuk memenuhi persyaratan pengolahan data yang legal dan transaksional, memberikan informasi kepada manajemen untuk mendukung kegiatan-kegiatan perencanaan, pengendalian, dan pengambilan keputusan, serta memberikan bermacam-macam laporan seperti yang diperlukan pihak luar

Tugas dari sistem informasi adalah untuk melakukan siklus pengolahan data. Untuk melakukan siklus ini, maka sebagai suatu sistem diperlukan komponen komponen tertentu. Telah diketahui bahwa data perlu diolah untuk dijadikan informasi yang berguna lewat suatu siklus. Siklus ini disebut siklus pengolahan data atau disebut juga dengan nama siklus informasi (Jogiyanto, 2009).

\section{Komponen Sistem Informasi}

Komponen-komponen sistem informasi adalah sebagai berikut:

\section{Blok Masukan (Input Block)}

Input mewakili data yang masuk ke dalam sistem informasi. Input di sini termasuk metode-metode dan media untuk menangkap data yang akan dimasukkan dapat berupa dokumen-dokumen dasar.

\section{Blok Model (Model Block)}

Blok ini terdiri dari kombinasi prosedur, logika dan model matematika yang akan memanipulasi data input dan data yang tersimpan di basis data dengan cara tertentu untuk menghasilkan keluaran yang diinginkan.

\section{Blok Keluaran (Output Block)}

Keluaran yang merupakan informasi yang berkualitas dan dokumentasi yang berguna untuk semua tingkatan manajemen serta pemakai sistem. 
4. Teknologi digunakan untuk menerima input, menjalankan model, menyimpan dan mengakses data, menghasilkan, mengirimkan keluaran dan membantu pengendalian dari sistem secara keseluruhan.

\section{Blok Basis Data (Database Block)}

Basis Data merupakan kumpulan dari data yang saling berhubungan satu dengan yang lainnya, tersimpan di perangkat keras komputer dan menggunakan perangkat lunak untuk memanipulasinya. Basis data diakses atau dimanipulasi dengan menggunakan perangkat lunak paket yang disebut dengan DBMS (Database Management System).

\section{Blok Kendali (Controls Block)}

Pengendali perlu dirancang dan diterapkan untuk meyakinkan bahwa hal-hal yang dapat merusak sistem dapat dicegah ataupun bila terlanjur terjadi kesalahan maka dapat langsung diatasi dengan cepat

\section{Pengertian Pendataan Pendidikan}

Menurut Kamus Besar Bahasa Indonesia (1991), pendidikan diartikan sebagai proses pembelajaran bagi individu untuk mencapai pengetahuan dan pemahaman yang lebih tinggi mengenai obyek-obyek tertentu dan spesifik. Pengetahuan tersebut diperoleh secara formal yang berakibat individu mempunyai pola pikir dan perilaku sesuai dengan pendidikan yang telah diperolehnya

Menurut buku Pedoman Pendataan Pendidikan (2003), pendataan pendidikan merupakan suatu kegiatan atau proses pembuktian yang ditemukan dari hasil penelitian yang dapat dijadikan dasar kajian atau pendapat yang dikaitkan dengan otonomi pendidikan pada khususnya dan otonomi daerah pada otonomi daerah pada umumnya.
Pendataan pendidikan mempunyai dua kegiatan utama yaitu (a) produksi data dan (b) pendayagunaan/pelayanan data. Produksi data merupakan kegiatan tersimpannya hasil pengumpulan data dalam sistem komputer, tersusunnya laporan-laporan periodik, dan tersusunnya berkas laporan untuk umpan balik pada sumber data.

Pendayagunaan/pelayanan data merupakan suatu cara untuk melakukan eksplorasi terhadap data berdasarkan pada perkembangan pembangunan pendidikan, kebutuhan pimpinan, atau permintaan data.

\section{Pengertian Pendidikan Non-formal}

Pendidikan adalah usaha manusia dalam meningkatkan pengetahuan tentang alam sekitarnya. Pendidikan diawali dengan proses belajar untuk mengetahui suatu hal kemudian mengolah informasi tersebut untuk diaplikasikan dalam kehidupan sehari-hari. Pendidikan nonformal adalah jalur pendidikan di luar pendidikan formal yang dapat dilaksanakan secara terstruktur dan berjenjang yang dibutuhkan masyarakat sekitar guna memenuhi kekurangannya di bidang pendidikan.

Lingkungan pendidikan non-formal merupakan lembaga kemasyarakatan dan atau kelompok sosial di masyarakat, baik langsung maupun tak langsung, ikut mempunyai peran dan fungsi edukatif (Tirtarahardja dan Sula). Dalam UndangUndang RI No. 20 Tahun 2003 tentang Sisdiknas Bab I Pasal 12 Pendidikan Nonformal adalah jalur pendidikan di luar pendidikan formal yang dapat dilaksanakan secara terstruktur dan berjenjang.

Bentuk penyelanggaraan pendidikan non-formal secara terstruktur dan berjenjang antara lain kursus komputer, 
kursus bahasa inggris, kelompok belajar paket A (setara dngan SD), kelompok belajar paket B (setara dengan SMP), paket C (setara dengan SMA) yang merupakan lembaga kursus yang mempunyai tingkat kecakapan. Adapun bentuk penyelenggaraan pendidikan yang tidak terstruktur dan tidak berjenjang misalnya informasi, penyuluhan, ceramah melalui media.

Tujuan pendidikan non-formal, mengembangkan potensi peserta didik dilembaga pendidikan dengan menekan meningkatnya masyarakat keaksaraan untuk memusatkan perhatian pada pelayanan bagi warga masyarakat yang tergolong kurang beruntung disebabkan a faktor ekonomi, dan kurangnya sarana dan prasana.

\section{Konsep Pemodelan Sistem}

\section{Flowchart}

Flowchart adalah bagan-bagan yang mempunyai arus yang menggambarkan langkah-langkah penyelesaian suatu masalah. penggambaran secara grafik dari langkah-langkah dan urut-urutan prosedur dari suatu program. Flowchart menolong analis dan programmer untuk memecahkan masalah kedalam segmen-segmen yang lebih kecil dan menolong dalam menganalisis alternatif-alternatif lain dalam pengoperasian

\section{Data Flow Diagram}

Data flow diagram sering digunakan untuk menggambarkan suatu sistem yang telah ada atau sistem baru yang akan dikembangakan secara logika tanpa mempertimbangkan lingkungan fisik dimana data tersebut mengalir (misalnya lewat telepon, surat dan sebagainya) atau lingkungan fisik diman data tersebut akan tersimpan (misalnya file kartu, microfiche, hard disk, tape, disket dan lain sebagainya).

\section{Entity Relationship Diagram (ERD)}

Entity Relationship Diagram merupakan gambaran sistematis model data yang berisi himpunan entitas dan himpunan relasi yang masing-masing dilengkapi dengan atribut-atribut yang mempresentasikan seluruh fakta.

\section{METODE PENELITIAN}

\section{Teknik Pengumpulan Data}

1) Interview adalah suatu metode pengumpulan data dengan cara tanya jawab atau wawancara secara langsung kepada pihak yang berwenang demi mendapatkan data yang dibutuhkan.

2) Observasi adalah suatu metode pengumpulan data dimana penelitian dilakukan secara langsung terhadap objek yang akan diteliti.

3) Kepustakaan adalah suatu metode pengumpulan data melalui buku dan internet yang digunakan dalam penyusunan penilitian ini.

\section{Analisa Sistem yang Berjalan}

Sistem yang berjalan merupakan sistem yang masih kovensional yang ada pada Dinas Pendidikan Nasional Kota Ternate dalam mengelola data hasil kelulusan siswa non-formal pada Dinas Pendidikan Nasional Kota Ternate. Berdasarkan analisis yang dilakukan, alur sistem yang berjalan disajikan pada gambar sebagai berikut : 


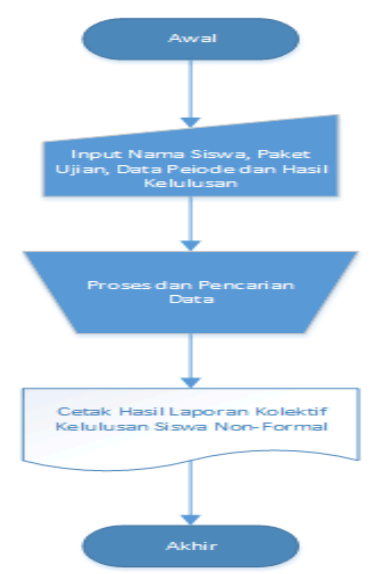

Gambar 1 : Flowchart Sistem Yang Berjalan

\section{Rancangan System yang Diusulkan}

Sistem yang diusulkan merupakan sistem yang baru untuk mengganti sistem yang masih konvensional dalam pengelolaan data hasil kelulusan siswa non-formal. Berikut alur sistem yang di usulkan.

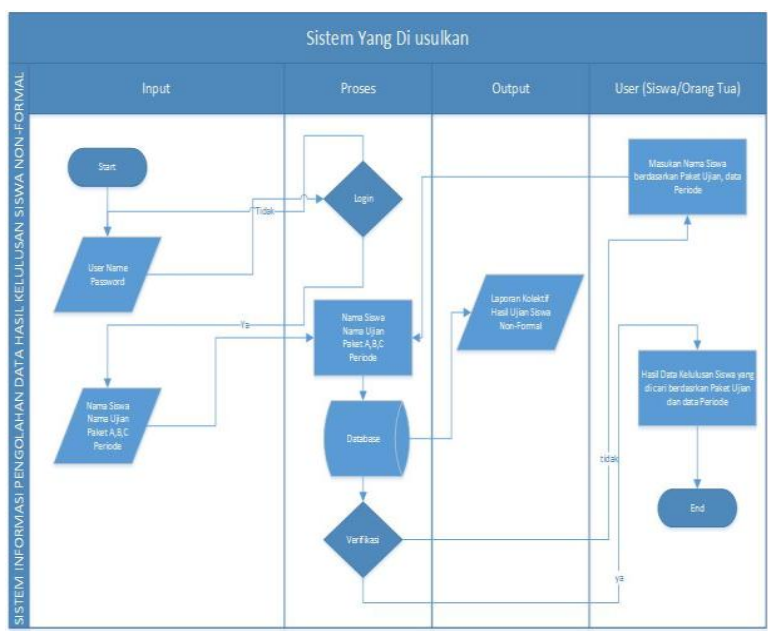

Gambar 2 : Flowchart Sistem Yang Diusulkan

\section{Kebutuhan Fungsional}

Kebutuhan fungsional adalah kebutuhan-kebutuhan yang memiliki keterkaitan langsung dengan sistem. Kebutuhan fungsional dari sistem ini meliputi:

1. Kebutuhan user a. Mendapatkan informasi hasil kelulusan siswa non-formal

b. Melihat informasi hasil kelulusan siswa non-formal

c. Berbagi informasi hasil kelulusan siswa non-formal

2. Kebutuhan administrator

a. Melakukan login ke system

b. Memanagement data website

\section{Kebutuhan Non-fungsional}

Kebutuhan non-fungsional adalah kebutuhan yang tidak secara langsung terkait dengan fitur tertentu di dalam system, yaitu:

1. Kebutuhan perangkat keras

a. Intel(R) Pentium $2.1 \mathrm{GHz}$

b. $R A M 2 \mathrm{~GB}$

c. Harddisk $500 \mathrm{~GB}$

2. Kebutuhan perangkat lunak

a. Sistem operasi microsoft windows 7 Ultimate

b. Notepad ++ sebagai script editor

c. Xampp 1.6.2 sebagai web server dan media database

d. Bahasa Pemograman PHP, MySql

e. Microsoft Visio di gunakan untuk pemodelan Sistem flowchart, DFD dan ERD

\section{PERANCANGAN SISTEM}

\section{Perancangan Tabel}

\begin{tabular}{|l|l|l|l|c|}
\multicolumn{9}{c|}{ Tabel 1: Admin } \\
\begin{tabular}{|l|l|l|} 
Field \\
Nama
\end{tabular} & $\begin{array}{l}\text { Data } \\
\text { Type }\end{array}$ & $\begin{array}{l}\text { Field } \\
\text { Size }\end{array}$ & Keterangan & $\begin{array}{l}\text { Primary } \\
\text { Key }\end{array}$ \\
\hline Id & Integer & 11 & $\begin{array}{l}\text { Penomoran } \\
\text { (PK) }\end{array}$ & $*$ \\
\hline User & Varchar & 9 & $\begin{array}{l}\text { User name } \\
\text { Login }\end{array}$ & \\
\hline Pass & Varchar & 8 & $\begin{array}{l}\text { Password } \\
\text { Login }\end{array}$ & \\
\hline
\end{tabular}

Tabel 2 : Ujian Paket

\begin{tabular}{|l|l|l|l|l|}
\hline Field Nama & $\begin{array}{l}\text { Data } \\
\text { Type }\end{array}$ & $\begin{array}{l}\text { Fiel } \\
\text { d } \\
\text { Siz } \\
\text { e }\end{array}$ & $\begin{array}{l}\text { Keterang } \\
\text { an }\end{array}$ & $\begin{array}{l}\text { Prima } \\
\text { ry } \\
\text { Key }\end{array}$ \\
\hline
\end{tabular}




\begin{tabular}{|l|l|l|l|l|}
\hline Id_peserta & $\begin{array}{l}\text { Intege } \\
\text { r }\end{array}$ & 11 & $\begin{array}{l}\text { Penomor } \\
\text { an (PK) }\end{array}$ & $*$ \\
\hline $\begin{array}{l}\text { Nama_Pesert } \\
\text { a }\end{array}$ & $\begin{array}{l}\text { Varch } \\
\text { ar }\end{array}$ & 9 & & \\
\hline No_Peserta & $\begin{array}{l}\text { Varch } \\
\text { ar }\end{array}$ & 8 & & \\
\hline Id_paket & $\begin{array}{l}\text { Intege } \\
\text { r }\end{array}$ & 11 & & \\
\hline $\begin{array}{l}\text { Nama_pelaja } \\
\text { ran }\end{array}$ & $\begin{array}{l}\text { Varch } \\
\text { ar }\end{array}$ & 5 & & \\
\hline Jumlah & $\begin{array}{l}\text { Varch } \\
\text { ar }\end{array}$ & 5 & & \\
\hline Rata-Rata & $\begin{array}{l}\text { Varch } \\
\text { ar }\end{array}$ & 5 & & \\
\hline Ket & $\begin{array}{l}\text { Varch } \\
\text { ar }\end{array}$ & 5 & & \\
\hline
\end{tabular}

\section{Diagram Konteks}

Diagram Konteks adalah uraian dari gambaran sistem secara keseluruhan, terdiri dari satu proses yang menggambarkan sistem tersebut terhubung dengan entitas eksternal. Diagram Konteks dari perancangan sistem dapat dilihat pada gambar sebagai berikut

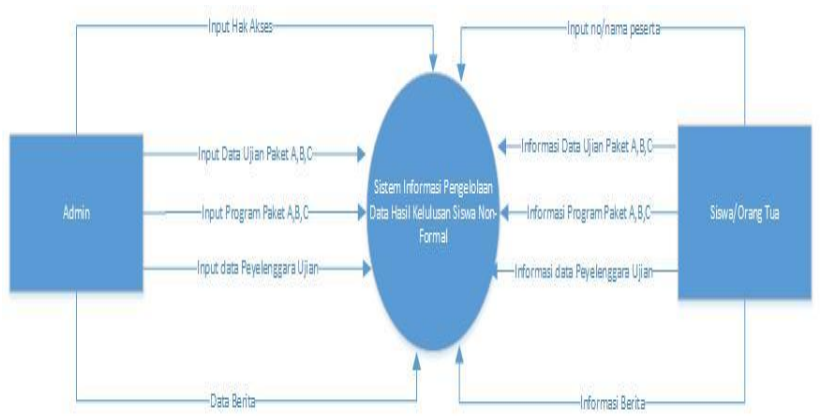

Gambar 3 : Diagram Konteks

\begin{tabular}{|l|l|l|l|l|}
\hline Field Nama & $\begin{array}{l}\text { Data } \\
\text { Type }\end{array}$ & $\begin{array}{l}\text { Field } \\
\text { Size }\end{array}$ & $\begin{array}{l}\text { Keterang } \\
\text { an }\end{array}$ & $\begin{array}{l}\text { Primar } \\
\text { y Key }\end{array}$ \\
\hline ID_paket & Integer & 11 & $\begin{array}{l}\text { Penomor } \\
\text { an (PK) }\end{array}$ & $*$ \\
\hline Paket & $\begin{array}{l}\text { Varcha } \\
\text { r }\end{array}$ & 30 & & \\
\hline thn_ajaran & $\begin{array}{l}\text { Varcha } \\
\text { r }\end{array}$ & 40 & & \\
\hline Propinsi & Integer & 11 & & \\
\hline kota_kab & $\begin{array}{l}\text { Varcha } \\
\text { r }\end{array}$ & 5 & & \\
\hline skb_pkbm & $\begin{array}{l}\text { Varcha } \\
\text { r }\end{array}$ & 5 & & \\
\hline Alamat & $\begin{array}{l}\text { Varcha } \\
\text { r }\end{array}$ & 5 & & \\
\hline Kecamatan & $\begin{array}{l}\text { Varcha } \\
\text { r }\end{array}$ & 5 & & \\
\hline $\begin{array}{l}\text { Kla_mata } \\
\text { Pelajaran }\end{array}$ & $\begin{array}{l}\text { Varcha } \\
\text { r }\end{array}$ & 5 & & \\
\hline rata_rata & $\begin{array}{l}\text { Varcha } \\
\text { r }\end{array}$ & 5 & & \\
\hline $\begin{array}{l}\text { Mdh_mata } \\
\text { pelajaran }\end{array}$ & $\begin{array}{l}\text { Varcha } \\
\text { r }\end{array}$ & 5 & & \\
\hline $\begin{array}{l}\text { Tgi_ mata } \\
\text { pelajaran }\end{array}$ & $\begin{array}{l}\text { Varcha } \\
\text { r }\end{array}$ & 5 & & \\
\hline $\begin{array}{l}\text { Dev_mata } \\
\text { pelajaran }\end{array}$ & $\begin{array}{l}\text { Varcha } \\
\text { reberhasila }\end{array}$ & 5 & & \\
\hline
\end{tabular}

\section{DFD Level 1}

DFD Level 1 adalah uraian dari gambaran sistem dari Diagram Konteks, terdiri dari beberapa proses yang menggambarkan sistem tersebut terhubung dengan entitas eksternal. DFD Level 1 dari perancangan sistem dapat dilihat pada gambar sebagai berikut:

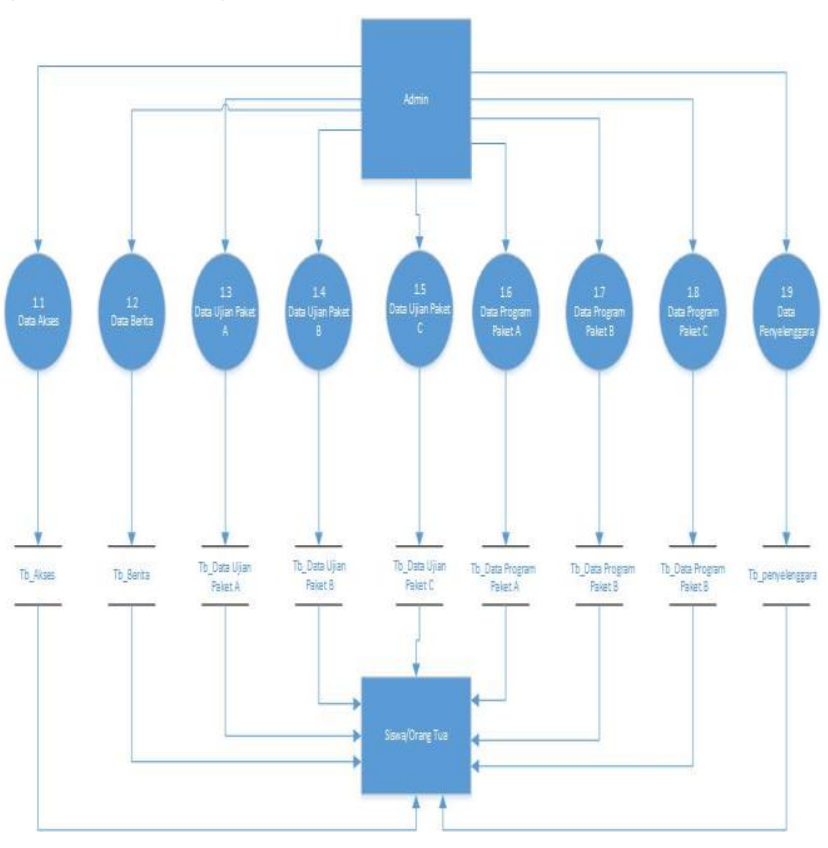

Gambar 4:DFD Level 1 


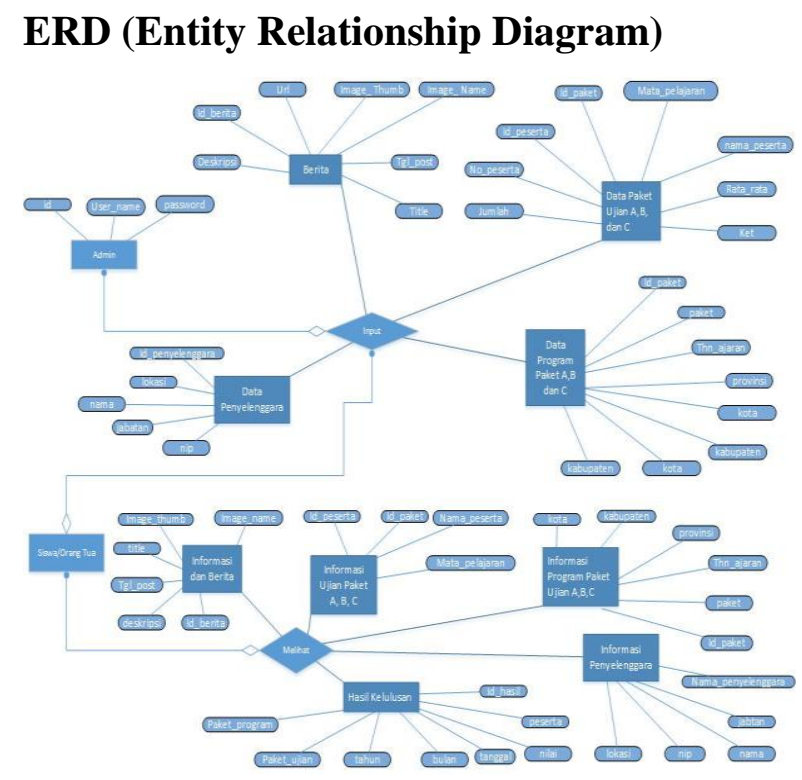

Gambar 5: ERD

\section{IMPLEMENTASI SISTEM \\ Menu Admin}

Pada halaman ini merupakan tampilan login yang ditampilkan kepada admin, pada halaman ini admin mengisi username dan password untuk masuk ke halaman admin

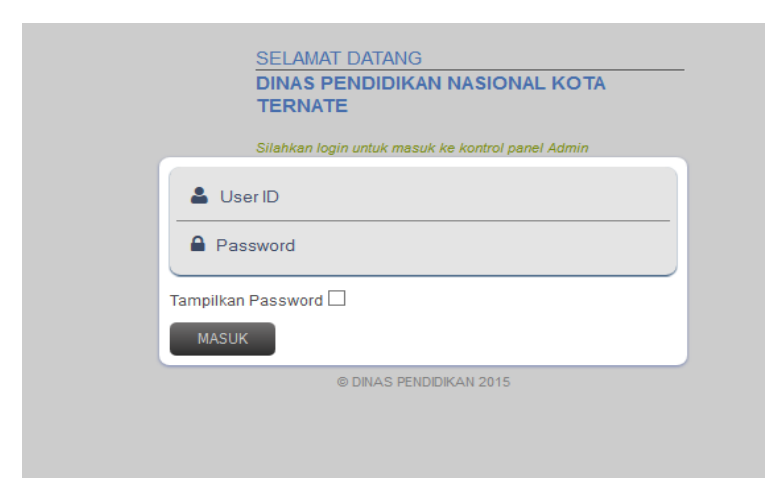

Gambar 6 : Menu Login Admin

\section{Menu berita dan Informasi}

Pada halaman ini merupakan tampilan berita dan informasi, pengunjung dapat melihat berita dan informasi.

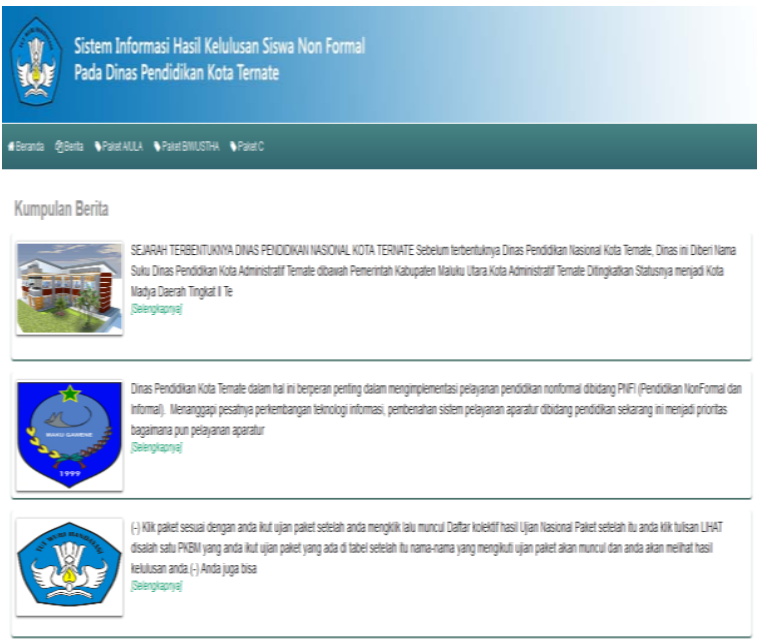

Gambar 7 : Menu Berita dan Informasi

\section{Menu data ujian paket}

Pada halaman ini merupakan tampilan data siswa hasil data kelulusan siswa, yang dapat dicari oleh pengunjung, Berikut merupakan menu data ujian paket dapat dilihat pada gambar sebagai berikut:

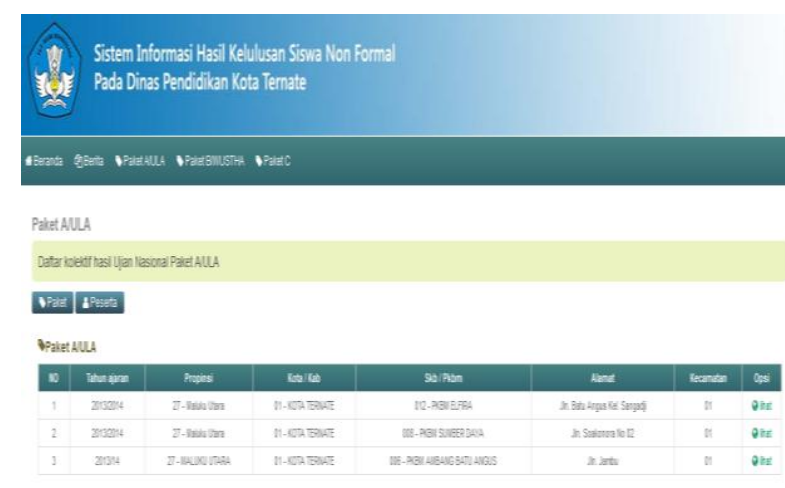

Gambar 8 : Menu Data Ujian Paket

\section{Menu data program paket}



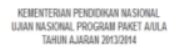

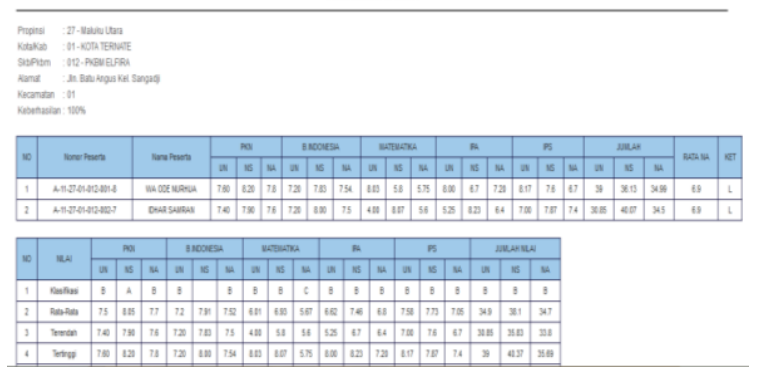

Gambar 9 : Menu Program Paket 
Menu data laporan



Gambar 10 : Menu Data Laporan

\section{KESIMPULAN}

Hasil perancangan sistem informasi pengolahan data kelulusan siswa nonformal disimpulkan sebagai berikut: 1) Sistem ini dibuat untuk mempermudah pihak instansi dalam mengelola data hasil kelulusan siswa non-formal serta memberikan informasi tentang data kelulusan bagi siswa non-formal.; 2) Mempermudah siswa non formal dan orang tua melihat hasil kelulusan pada system dimana saja.

Berdasarkan kesimpulan di atas, maka diajukan saran sebagai berikut.: 1) System informasi ini dapat diimplementasi pada instansi tersebut untuk mengganti system yang masih konvesional.: 2) Untuk pengembangan berikutnya agar system informasi yang dirancang dapat memberikan hasil dan fitur yang maksimal.

\section{DAFTAR PUSTAKA}

Kamus Besar Bahasa Indonesia 1991, Pusat Data dan Informasi Pendidikan Depdiknas., 2003. Pedoman Pendataan Pendidikan. Jakarta.

A,Kristanto. 2007. Analisis dan Desain Sistem Informasi, Yogyakarta, Penerbit Andi.

Jogiyanto. (2009). Sistem Teknologi Informasi. Yogyakarta: Andi
Zaki, Ali. 36 menit belajar komputer PHPdan MySQL, Jakarta : PT Elex Media Komputindo, 2008.

Nugroho, Adi. 2010. Rekayasa Perangkat Lunak Berorientasi Objek dengan metode USDP. Andi offset: Yogyakarta.

Azhar Susanto (2007), Sistem Informasi Manajemen Konsep dan Pengembangannya. Edisi 3. Lingga Jaya. Bandung

Muharto, Arisandy Ambarita, 2016, Metode Penelitian Sistem Informasi, Deepublish, Yogyakarta

Titin Purnamasari, Pembangunan Sistem Informasi Pengolahan Data Pegawai Dan Penggajian Pada Unit Pelaksana Teknis Taman Kanak-Kanak Dan Sekolah Dasar Kecamatan Pringkuku, Journal Speed - Sentra Penelitian Engineering dan Edukasi - Volume 5 No 2 - 2013 - ijns.org, ISSN : 19799330 (Print) - 2088-0154 (Online)

Susy Kusuma Wardani, Sistem Informasi Pengolahan Data Nilai Siswa Berbasis Web Pada Sekolah Menegah Atas (SMA) Pacitan, Indonesian Jurnal on Networking and Security (IJNS) ijns.org, IJNS Volume 2 No 2 - April 2013 - ISSN: 2302-5700

Azhar Irfandi, Okta Liansyah, Ervi Cofriyanti, Hermawan, Analisis dan Perancangan Sistem Informasi Akademik (Studi Kasus SMA Negeri 1 Talang Kelapa Palembang) Jatisi, Vol. 1 No. 1 September 2014, ISSN : 24074322

Thomas Afrizal, Dwi Yulistyanti, Analisis dan Perancangan Sistem Informasi Pendataan Pendidikan Kota "D”, Seminar Nasional Teknologi Informasi dan Multimedia 2015 STMIK AMIKOM Yogyakarta, 6-8 Februari 2015, ISSN : 2302-3805 